$$
y_{0}^{2 m}
$$


Distribuclón del ingreso e incidencia de la pobreza a lo largo del ajuste

Oscar Altimir

Nuevas orientaciones para la gestión pública

Eugenio Lahera

Industrias petroquímica y de máquinas herramientas:

estrategias empresariales

Daniel Chudnovsky, Andrés López y Fernando Porta

Productividad, crecimiento y exportaciones industriales de Brasil

Regis Bonelli

Maquila en el Caribe: la experiencia de Jamaica

Larry Willmore

Elasticidad-precio de las exportaciones agrícolas de Centroamérica

De la inflaclón crónica a la inflación moderada en el Ecuador

Luis I. Jácome Hidalgo

Nuevas estrategias de las empresas transnacionales en la Argentina

Bernardo Kosacoff y Gabriel Bezchinsky

Informalidad y pobreza en América Latina

Guillermo Rosenbluth

Crisis y alternativas en los procesos de regionalización

Sergio Boisier

Una perspectiva cultural de las propuestas de la CEPAL

Fernando Calderón, Martín Hopenhayn y Ernesto Ottone

La CEPAL y el neoliberalismo: entrevista a Fernando Fajnzylber

Orientaciones para los colaboradores de la Revista de la CEPAL

Publicaciones reclentes de la CEPAL 


\begin{tabular}{|l|l|}
\cline { 2 - 3 } & REVISTA DE LA CEPAL 52 \\
\hline
\end{tabular}

\section{Maquila en el Caribe: \\ la experiencia \\ de Jamaica}

\section{Larry Willmore}

Oficial de Asuntos

Económicos en la Subsede

de la CEPAL para el Caribe.
La industria maquiladora, llamada también industria procesadora de exportaciones, es una actividad ampliamente difundida en México y Centroamérica, y que cobra cada vez mayor importancia para las economías del Caribe. Los países de la subregión han logrado atraer tanto la inversión extranjera como la nacional a la industria del ingreso y procesamiento de datos, al armado y la fabricación de vestuario y calzado, y al montaje de equipo eléctrico y electrónico, de juguetes y de otros bienes de exportación. Los inversionistas aprecian el bajo costo de la mano de obra y la ausencia de controles cambiarios y de restricciones burocráticas, así como la promesa de exención de todos los impuestos, inciuidos aquellos sobre las utilidades y los impuestos a las importaciones de equipo, materias primas y bienes intermedios utilizados en la producción para la exportación. Las economías locales reciben divisas, puesto que la moneda local tiene que adquirirse en el Banco Central a fin de pagar los salarios y otros gastos efectuados en el país. Además, se benefician de la generación de empleo, de posibles eslabonamientos con la economía nacional y de la transferencia de tecnología. Este artículo es un estudio de caso basado en investigaciones realizadas en Jamaica en junio de 1993, sobre el uso que hace el país de este instrumento para su desarrollo industrial. En él se sostiene que los beneficios para Jamaica se ven menoscabados por políticas descaminadas que confinan a los exportadores a enclaves económicos y limitan su contacto con el resto de la economía. 


\section{I}

\section{Introducción}

Con dos y medio millones de habitantes, Jamaica es la nación más grande de los 13 países anglohablantes de la Comunidad del Caribe (CARICOM). Es también la isla anglófona más grande del Caribe, aunque su territorio sólo representa la mitad del de Belice y poco más de un décimo del de Guyana.

En la década de 1970 y comienzos de la de 1980, Jamaica experimentó una severa y prolongada recesión económica. De hecho, su producto interno bruto se contrajo a una tasa media anual de $1.0 \%$ entre 1970 y 1985 , lo que representó con creces el peor desempeño entre los 23 países que figuran en el Anuario Estadistico de América Latina y el Caribe, que publica la CEPAL. La recesión provocó tasas de desempleo que superaron el $25 \%$ de la fuerza de trabajo. La falta de oportunidades de empleo, sumada a la tensión social, estimuló una emigración considerable de personal calificado, incluido el de gestión. En 1986 comenzó una modesta recuperación que prosigue hasta hoy. No obstante, la economía sigue siendo muy dependiente de la exportación de unos pocos productos básicos tradicionales con precios deprimidos en los mercados mundiales. El valor de las exportaciones de cuatro productos básicos —alúmina, bauxita, azúcar y bananas- equivalió a dos tercios de todas las exportaciones de mercancías en 1991 y $1992 .{ }^{1}$

En un esfuerzo por obtener divisas y ofrecer empleo productivo a su población, Jamaica se ha volcado cada vez más al fomento del turismo y de la industria maquiladora. Se estima que en 1992 los ingresos brutos del turismo fueron de 850 millones de dólares, es decir, $11.3 \%$ más que en 1991. Las exportaciones de vestuario, que comprenden el grueso de la actividad maquiladora de la isla, llegaron a un total de 384 millones de dólares en 1992, es decir, 28.7\% más que en 1991.

\section{II}

\section{Una reseña de la industria maquiladora}

La economía insular da empleo a más de 900 mil personas, de las cuales 100 mil trabajan en el sector manufacturero, 26 mil en el subsector hotelero (alojamiento turístico) y 31 mil en las empresas maquiladoras. Por ende, la industria maquiladora ofrece más de $3 \%$ de todos los puestos de trabajo en la economía y casi un tercio de los empleos en el sector manufac-

\footnotetext{
1 El valor de las exportaciones de los cuatro productos básicos indicados fue de 788 millones de dólares en 1991 y, por baja de los precios, de 682 millones de dólares en 1992. Las exportaciones totales de mercancías en esos mismos años ascendieron a 1151 millones y 1053 millones de dólares, respectivamente (Instituto de Planificación de Jamaica, 1993, cuadros 3.1 y 3.4). Los datos sobre el comercio de mercancías excluyen las exportaciones de las zonas francas, pero incluyen las exportaciones de manufacturas de las fábricas situadas en el territorio aduanero. Los gastos locales de las empresas de las zonas francas se clasifican como exportaciones de servicios. Las plantas maquiladoras situadas en el territorio aduanero realizan exactamente las mismas actividades que las de las zonas francas, de modo que el trato dispar que se da a las exportaciones de unas y otras resulta confuso para los usuarios de las estadísticas de comercio jamaiquinas.
}

turero. Aunque sólo se dispone de datos parciales, poca duda cabe de que los puestos de esta industria están ocupados predominantemente por mujeres, especialmente jóvenes. ${ }^{2}$ Algunos investigadores sostienen que esto tiene el efecto de atraer a los trabajadores secundarios hacia la fuerza de trabajo en vez de reducir la tasa de desempleo de los jefes de hogar. Por otra parte, las jóvenes jamaiquinas suelen ser jefes de familia sin cónyuge, y es precisamente este grupo demográfico - mujeres jóvenes - el que registra la tasa más elevada de desempleo en la isla. ${ }^{3}$

La mayor parte de la actividad maquiladora de

\footnotetext{
2 Se ha señalado que $88.9 \%$ del personal que trabajaba en cinco fábricas de vestuario de la Zona Libre de Kingston a fines de los años ochenta estaba constituido por mujeres (CEPAL, 1990, p. 41). En la Zona Franca Garmex, según datos inéditos, el personal femenino asciende al $86.0 \%$ en 1991 y al $82.6 \%$ en 1992 .

3 En 1992 la tasa de desempleo global de la fuerza de trabajo era de $15.7 \%$, pero para las mujeres menores de 25 años llegaba al $40.5 \%$, y al $17.9 \%$ para los hombres menores de 25 años (Instituto de Planificación de Jamaica, 1993, cuadros 16.7 y 16.8).
} 
Jamaica está dedicada a la fabricación de vestuario: dos tercios de las empresas y casi $90 \%$ del empleo (cuadro 1). Le sigue en importancia la industria de procesamiento de datos, pero las empresas de este rubro son pequeñas comparadas con las plantas manufactureras, de modo que 26 de ellas sólo emplean a $8 \%$ de los trabajadores del sector. Las maquiladoras están situadas en las zonas francas, y también en ciudades, pueblos y aldeas de toda la isla.

CUADRO 1

Jamaica: Empresas maquiladoras y empleo en ellas, diciembre de 1992

\begin{tabular}{|c|c|c|c|c|}
\hline & \multicolumn{2}{|c|}{ Empresas } & \multicolumn{2}{|c|}{ Empleo } \\
\hline & $\mathrm{N}^{o}$ & $\overline{\%}$ & Personas ocupadas & $\%$ \\
\hline \multicolumn{5}{|l|}{ Territorio aduanero ${ }^{a}$} \\
\hline Vestuario & 50 & 71.4 & 15300 & 90.1 \\
\hline Procesamiento de datos & 20 & 28.6 & 1678 & 9.9 \\
\hline Sub total & 70 & 100.0 & 16978 & 100.0 \\
\hline \multicolumn{5}{|l|}{ Zonas francas } \\
\hline Vestuario & 24 & 61.5 & 12683 & 89.5 \\
\hline Procesamiento de datos & 6 & 15.4 & 867 & 6.1 \\
\hline Telemercadeo & 3 & 7.7 & 116 & 0.8 \\
\hline Otras & 6 & 15.4 & 506 & 3.6 \\
\hline Subtotal & 39 & 100.0 & 14172 & 100.0 \\
\hline \multicolumn{5}{|c|}{ Territorio aduanero más zonas francas } \\
\hline Vestuario & 74 & 67.9 & 27938 & 89.0 \\
\hline Procesamiento de datos & 26 & 23.9 & 2545 & 8.2 \\
\hline Otras & 9 & 8.2 & 622 & 2.0 \\
\hline Total general & 109 & 100.0 & 31150 & 100.0 \\
\hline
\end{tabular}

Fuente: Estimaciones de la CEPAL sobre la base de datos suministrados por la Jamaica Promotion Corporation (JAMPRO), la Zona Libre de Kingston, la Zona Libre Garmex y la Zona Libre de Montego Bay.

a Incluye un número desconocido pero pequeño de plantas de vestuario situadas fuera de las zonas francas que han obtenido el régimen jurídico de zona franca.

\section{Empresas de las zonas francas}

De las 109 empresas maquiladoras hay 39 que absorben el $45.5 \%$ del empleo y que están situadas en las tres zonas francas de propiedad fiscal (cuadro 1). La zona franca de Kingston, la más antigua y grande de las tres, se halla en el corazón industrial de esa ciudad, adyacente a un puerto moderno. Se estableció en mayo de 1976, pero tuvo un arranque lento y no atrajo a muchos inversionistas hasta después de 1982. La zona franca Garmex, segunda en tamaño, se estableció en 1987 a sólo dos kilómetros de distancia de la de Kingston. La zona franca de Montego Bay, situada al suroeste de la segunda ciudad de Jamaica y principal destino turístico de la isla, se estableció en 1982 pero sólo comenzó a operar en 1985.

En 1989 se inauguró en la zona franca de Montego Bay el Digipuerto Internacional de Jamaica para suministrar comunicaciones por satélite a bajo costo a las empresas de procesamiento de datos y de telemercadeo. El Digipuerto ofrece a sus clientes velocidades que oscilan entre 9600 y 1544 megabits por segundo, números telefónicos internacionales (800) con llamada gratuita, autorización de tarjetas de crédito para venta directa, y tarifas desde 24 centavos de dólar por minuto para llamadas a los Estados Unidos.

Las empresas de las zonas francas tienen que pagar los salarios y otros gastos locales en moneda nacional, pero pueden mantener cuentas en moneda extranjera y están exentas a perpetuidad de los impuestos que gravan las utilidades, las importaciones de la zona y las exportaciones a países distintos de Jamaica. Pero lo más importante es que también están liberadas de muchos de los trámites administrativos ligados a la importación y la exportación. Su actividad principal es la confección de vestuario, pero la zona franca de Kingston alberga también una fábrica de confites y una planta de etanol. En la zona franca de Montego Bay hay cierta actividad en materia de procesamiento de datos, telemercadeo y montaje de equipo eléctrico y electrónico.

\section{Empresas situadas en el territorio aduanero}

Fuera de las zonas francas funcionan unas $70 \mathrm{em}-$ presas maquiladoras (cuadro 1). Se dedican exclu- 
sivamente a las industrias del vestuario y del procesamiento de datos y emplean, en conjunto, más mano de obra que las empresas de las zonas francas. Salvo raras excepciones, estas empresas, a semejanza de sus contrapartes de las zonas francas, producen exclusivamente para los mercados de exportación.

Algunas de las industrias de vestuario han conseguido que el gobierno les permita acogerse al régimen jurídico de zona franca. El resto de ellas, y algunas de las dedicadas al procesamiento de datos, operan de conformidad con la Ley de Fomento de la Industria de Exportación, promulgada en 1956 y que otorga a las empresas autorizadas una exoneración tributaria sobre las utilidades y dividendos, así como la exención de pago de derechos sobre los bienes de capital y materias primas importados. Dichos incentivos se otorgan por un máximo de diez años, pero para las empresas es fácil cambiar su razón social cada cinco o diez años y así obtener de hecho incentivos a perpetuidad. Por ende, el régimen de dicha ley ofrece a los exportadores instalados en el territorio aduanero casi todos los beneficios asociados al régimen jurídico de zona franca. La diferencia principal estriba en que estos exportadores no están liberados de los controles cambiarios ni de las restricciones cuantitativas a las importaciones. En los últimos años, con la abolición de los controles cambiarios y la eliminación de las cuotas de importación, las diferencias entre ambos regímenes se han vuelto insignificantes.

\section{Fabricación de vestuario}

El empleo en esta industria ha aumentado de unas 6000 personas en 1982 y 1983 a más de 28000 en la actualidad (cuadro 2). Esto supone una tasa media de crecimiento de más de 19\% anual entre 1983 y 1992; pero el empleo creció con mucho mayor rapidez hasta fines de 1987 que en años posteriores.

Estos datos no establecen distinciones entre los exportadores y las empresas que producen para el mercado interno, pero a los exportadores se debe todo el crecimiento del empleo y, en especial después de 1983, el empleo de casi todas las personas ocupadas. Las exportaciones de ropa aumentaron sostenidamente entre 1983 y 1992 (de 10.7 millones de dólares a 384.4 millones) y alcanzaron su máximo crecimiento entre 1984 y 1988 (cuadro 3). En 1991 y 1992 casi $60 \%$ de las exportaciones provino de las empresas de las zonas francas; la cifra fue de $15 \%$ en $1982,30 \%$
CUADRO 2

Jamaica: Empleo en la industria del vestuario, 1982-1992

(Personas ocupadas)

\begin{tabular}{lccr}
\hline & Territorio aduanero $^{a}$ & Zonas francas & Total \\
\hline 1982 & 5.741 & 450 & 6.191 \\
1983 & 4.958 & 939 & 5.897 \\
1984 & 5.125 & 2.704 & 7.829 \\
1985 & 5.320 & 3.180 & 8.500 \\
1986 & 11.527 & 7.399 & 18.926 \\
1987 & 12.752 & 10.830 & 23.582 \\
1988 & 14.089 & 6.490 & 20.579 \\
1989 & 17.986 & 7.355 & 25.341 \\
1990 & 14.200 & 10.300 & 24.500 \\
1991 & 16.500 & 11.000 & 27.500 \\
1992 & 16.000 & 12.700 & 28.700 \\
\hline
\end{tabular}

Fuente: CEPAL, sobre la base de datos suministrados por la Jamaica Promotions Corporation (JAMPRO), la Zona Franca de Kingston, la Zona Franca Garmex, la Zona Franca de Montego Bay y el Instituto Textil y del Vestuario de Jamaica.

a Incluye un número desconocido pero escaso de plantas de vestuario situadas fuera de las zonas francas que han obtenido el régimen jurídico de zona franca.

en 1983-1984 y 55\% en 1990 . Más de la mitad de las exportaciones correspondió a vestuario confeccionado a partir de tela cortada en los Estados Unidos, a fin de beneficiarse de la partida aduanera 807 de ese país (actualmente se denomina HS 9802.00.80) y pagar derechos solamente por el valor agregado en Jamaica. Menos de la mitad del valor de las exportaciones corresponde a la variedad "corte, confección y acabado", que es la que crea más empleo en la isla por

CUADRO 3

Jamaica: Exportaciones de vestuario, 1982-1992a

\begin{tabular}{lccc}
\hline Año & $\begin{array}{c}\text { Total } \\
\text { (millones de } \\
\text { dólares) }\end{array}$ & $\begin{array}{c}\text { Zona franca } \\
(\%)\end{array}$ & $\begin{array}{c}\mathrm{CCA}^{\mathrm{b}} \\
(\%)\end{array}$ \\
\hline 1982 & 14.1 & 15.0 & 18.2 \\
1983 & 10.7 & 30.9 & 29.9 \\
1984 & 27.4 & 30.6 & 40.8 \\
1985 & 55.9 & 47.8 & 39.7 \\
1986 & 101.7 & 48.6 & 42.6 \\
1987 & 184.8 & 46.3 & 45.3 \\
1988 & 220.9 & 52.9 & 47.6 \\
1989 & 243.2 & 49.6 & 41.4 \\
1990 & 277.8 & 55.3 & 48.2 \\
1991 & 298.7 & 59.3 & 46.6 \\
1992 & 384.4 & 57.8 & 42.2 \\
\hline
\end{tabular}

Fuente: Jamaica Promotions Corporation (JAMPRO), (División de Comercio Internacional).

a Excluye las exportaciones a miembros de la CARICOM

b Se refiere a las exportaciones sometidas a corte, confección y acabado, para distinguirlas de las correspondientes al armado a maquila de ropa con tela precortada. 
dólar de exportaciones, aunque la tela sea siempre importada.

La tela que se utiliza en la confección de ropa acogida a la partida 807 se fabrica y corta cada vez más en los Estados Unidos, a fin de cumplir con los requisitos del programa de acceso especial (807A/9802A) de la Iniciativa para la Cuenca del Caribe, conocido también como el "super 807". A través de este programa, los Estados Unidos ha otorgado a la isla cuotas de acceso generosas, conocidas como niveles de acceso garantizados. En virtud de esta partida Jamaica fue el principal proveedor de calcetería y ropa interior del mercado estadounidense en 1992. Sin embargo, los exportadores no experimentaron restricciones debido a las cuotas, pues sólo se ocupó el $91 \%$ de ellas en calcetería, el $75 \%$ en ropa interior y el $65 \%$ en las camisas de punto.

Los Estados Unidos es el mercado principal de la industria de prendas de vestir de Jamaica: $80 \%$ de las exportaciones de este rubro van ahora a dicho país, mientras que la Comunidad Europea, que adquirió el $17.6 \%$ de estas exportaciones en 1992, le sigue en importancia. El mercado de la CARICOM, que absorbió casi un tercio de las exportaciones textiles en 1982 y 1983, es ahora minúsculo. El mercado canadiense sigue siendo pequeño, aunque está creciendo, lo que refleja el hecho de que los textiles y el vestuario no están incluidos en el comercio preferencial del CARIBCAN (programa de comercio exterior, inversiones y cooperacion industrial entre el Canadá y los países del Caribe asociados a la mancomunidad Británica de Naciones).

\section{Procesamiento de datos}

Diez años atrás sólo existían cinco empresas dedicadas al ingreso y procesamiento de datos en todo Jamaica, que servían en su mayor parte el mercado interno. La industria creció con rapidez cuando el gobierno, conforme a la Ley de Fomento de la Industria de Exportación, ofreció otorgar incentivos a las empresas que estuvieran dispuestas a especializarse en los mercados de exportación y prescindir de los clientes nacionales. Estos servicios se exportan casi exclusivamente a los Estados Unidos. En
1985 el gobierno dispuso, respecto de los servicios de ingreso de datos, que a diferencia de las manufacturas, los privilegios de exoneración tributaria y de importaciones libres de derechos se restringirían en lo sucesivo a las empresas situadas en las zonas francas. En la práctica, esto significa que las empresas tienen que trasladarse a la zona franca de Montego Bay, pues no existen las instalaciones requeridas en las demás zonas francas. Por ende, los últimos incentivos otorgados conforme a la Ley de Fomento de la Industria de Exportación terminarán en 1995, de modo que cabe preguntarse si esta industria mantendrá su tamaño actual de 26 empresas con más de 2500 empleados.

No hay razones técnicas para concentrar el procesamiento de datos en un solo lugar geográfico: el Digipuerto de Montego Bay puede proveer, $\mathrm{y}$ de hecho provee, servicios por conducto de las líneas telefónicas locales a las empresas de Kingston y de otras partes de la isla. En cambio, hay un argumento convincente para la descentralización: la falta de transporte público, sobre todo avanzada la noche, lo que reviste importancia en una industria que funciona cuando menos con dos, y generalmente tres, turnos diarios.

Las importaciones libres de derechos tienen menos importancia para las empresas de procesamiento de datos que para los fabricantes de ropa, ya que las primeras no importan materias primas ni bienes intermedios. Pero en cambio sí les interesa el acceso a los bienes de capital más modernos a fin de mantener su margen competitivo. Por ejemplo, Jamaica compite con México septentrional, que posee la ventaja de estar próximo a su mercado principal (los Estados Unidos), y con Filipinas, que cuenta con la ventaja del idioma inglés y de un enlace de fibra óptica con los Estados Unidos. Además, el procesamiento de datos, a diferencia de la fabricación de vestuario, no está protegido por restricciones de cuotas o acuerdos internacionales de repartición de mercados. En la actualidad es posible que una empresa obtenga una exención de derechos para la importación de determinados bienes de capital, pero este es un proceso oneroso y lento comparado con la exención automática que otorgan la ley de fomento de la idustria de exportación o el régimen jurídico de zona franca. 


\section{III}

\section{Nacionalidad de la propiedad}

En las zonas francas de Jamaica hay una notoria ausencia de empresas jamaiquinas. De las 39 industrias de exportación ubicadas allí, sólo tres son de propiedad de jamaiquinos, y todas están situadas en la zona franca de Montego Bay. Roberts (1991, p. 167) hace gran caudal de este hecho en una tesis reciente; al comparar las zonas francas de Jamaica con las de Mauricio, observa con beneplácito que en este último la participación del capital nacional ha aumentado de un 30\% en 1983 a 53\% en 1990.

El hecho de que en jamaica tan pocas empresas de la zona franca sean de propiedad jamaiquina obedece en gran medida a la política gubernamental. Después de todo, las zonas francas se establecieron para atraer la inversión externa y no la interna. El gobierno exige que la inversión en ellas sea en divisas, y hasta hace poco era ilegal que los residentes de la isla tuvieran efectivo o cuentas en moneda extranjera. El único fabricante de vestuario jamaiquino instalado en una zona franca recurría al subterfugio de establecer una empresa mixta con capital de las Islas Caimán a fin de traer divisas al país. La única empresa nacional de procesamiento de datos lleva el nombre de Bay Telemarketing Agency porque sólo pudo obtener aprobación para operar como agencia de telemercadeo, lo que casi no exige inversión en equipo. A poco andar, la empresa se diversificó hacia el procesamiento de datos y dejó de lado el telemercadeo.

La poca presencia de empresas jamaiquinas en las zonas francas refleja asimismo la preferencia de los empresarios insulares por los emplazamientos situados fuera de ellas. El gerente de la Bay Telemarketing Agency manifestó con mucha franqueza que su empresa abandonaría la zona, o cuando menos establecería una oficina satélite en otra ubicación, si eso pudiera hacerse sin perder incentivos a las exportaciones. Se quejó de que la afluencia de empresas de procesamiento de datos redundaba en una fuerte competencia por un pequeño núcleo de operadores capacitados. Aunque las empresas capaciten a sus propios operadores, inevitablemente los pierden atraídos por otras firmas situadas en el mismo recinto.

El Director Gerente de Davon Corporation Ltd., la exportadora de ropa más antigua y más grande de propiedad jamaiquina, ${ }^{4}$ estima que el requisito de invertir fondos extranjeros no fue jamás un factor que disuadiera a su empresa de invertir en una zona franca. En cambio, dio tres razones por las cuales su empresa decidió ubicar sus plantas lejos de las zonas francas establecidas:

i) En las zonas francas hay estrangulamientos inevitables en materia de transporte cuando miles de trabajadores tratan de abordar los buses al mismo tiempo.

ii) En esas zonas las dificultades laborales en una planta afectan el estado de ánimo del personal en todas las demás, ya que los trabajadores conviven en los recesos para el almuerzo y al término de la jornada.

iii) Los alquileres de los galpones industriales en las zonas francas ( 3.50 dólares por pie cuadrado por año en la de Kingston y 4.25 dólares en las otras dos) son mucho más elevados que los que se cobran por instalaciones similares en otros lugares.

Fuera de las zonas francas hay 70 maquiladoras cuyas actividades son prácticamente indistinguibles de las que realizan las 39 empresas dentro de esas zonas. De esas maquiladoras 48 son de propiedad de residentes de Jamaica. Sin embargo, no puede aseverarse que las 48 sean de propiedad jamaiquina; en el caso de las 20 empresas procesadoras de datos que operan en el territorio aduanero sólo se sabe que la abrumadora mayoría pertenece a nacionales.

En la propiedad de las 109 maquiladoras predomina la nacionalidad jamaiquina, con alrededor de 51 empresas (46.8\% del total). Sin embargo, en promedio las empresas de jamaiquinos son mucho más pequeñas que las empresas de propiedad extranjera, de modo que ofrecen menos de un cuarto del empleo total del sector procesador de exportaciones (cuadro 4). Le siguen en número las de estadounidenses con 36 plantas. Luego vienen las de chinos de Hong Kong con 13 plantas y de nacionales de la República de Corea con siete. A fines de 1992 había también una planta de

\footnotetext{
${ }^{4}$ Davon Corporation opera una planta en Kingston, otra en Montego Bay (Windmill Garments) y una tercera cerca de Ocho Ríos (International Apparel). La empresa alquila al gobierno el galpón industrial de Montego Bay, y es dueña de las otras dos propiedades.
} 
CUADRO 4

Jamaica: Empresas maquiladoras según su nacionalidad, 1992

\begin{tabular}{lrrrrr}
\hline Nacionalidad & \multicolumn{2}{c}{ Empresas } & & \multicolumn{2}{c}{ Empleo } \\
\cline { 2 - 3 } \cline { 5 - 6 } & Número & Porcentaje & & $\begin{array}{c}\text { Personas Porcentaje } \\
\text { ocupadas }\end{array}$ \\
\hline Jamaica a & 51 & 46.8 & & 7479 & 24.0 \\
Estados Unidos & 36 & 33.0 & & $\ldots$ & $\ldots$ \\
Hong Kong & 13 & 11.9 & & $\ldots$ & $\ldots$ \\
República de Corea & 7 & 6.4 & & $\ldots$ & $\ldots$ \\
Otros & 2 & 1.8 & & 23671 & 76.0 \\
Total & 109 & 100.0 & 31150 & 100.0 \\
\hline
\end{tabular}

Fuente: Estimaciones de la CEPAL sobre la base de datos suministrados por la Jamaica Promotions Corporation (JAMPRO), la Zona Franca de Kingston, la Zona Franca Garmex y la Zona Franca de Montego Bay.

a Se supone que la totalidad de las 20 empresas de procesamiento de datos situadas fuera de las zonas francas son de propiedad jamaiquina.

propiedad de inversionistas del Reino Unido y otra de inversionistas del Canadá.

Respecto a la industria del vestuario, la Jamaica Promotions Corporation (JAMPRO) ha tabulado los datos históricos sobre las exportaciones correspondientes al período 1982-1991 según la nacionalidad de la empresa. Estos datos figuran en el cuadro 5, pero las exportaciones a la CARICOM se han deducido de las exportaciones de las empresas jamaiquinas bajo el supuesto (realista) de que sólo estas empresas exportan a ese mercado protegido. Entre 1982 y 1984 las empresas jamaiquinas dominaron la industria, con alguna participación de las empresas estadounidenses y una virtual ausencia de las asiáticas (de Hong Kong y de la República de Corea). En 1985 y 1986 las exportaciones provinieron casi por partes iguales de los tres grupos de empresas. Posteriormente, las exportaciones de las empresas estadounidenses y asiáticas crecieron con mucho mayor rapidez que las de las empresas nacionales. En 1991 la participación jamaiquina había caído a $20 \%$, mientras que la de las empresas estadounidenses y asiáticas había aumentado a $39 \%$ y $41 \%$, respectivamente.

En el cuadro 5 interesa observar que las exportaciones de las empresas asiáticas realizan casi todas actividades de "corte, confección y acabado", es decir, el corte y la costura de telas importadas (siempre provenientes de Asia). En cambio, en las exportaciones de las empresas jamaiquinas y estadounidenses predomina, aunque no en forma exclusiva, el armado de tela precortada acogido a la partida 807 .

CUADRO 5

Jamaica: Exportaciones de vestuario por nacionalidad de la empresa, 1982-1992 a (Millones de dólares y porcentajes)

\begin{tabular}{|c|c|c|c|c|c|c|}
\hline & \multicolumn{2}{|c|}{$\begin{array}{l}\text { Empresas } \\
\text { jamaiquinas }\end{array}$} & \multicolumn{2}{|c|}{$\begin{array}{c}\text { Empresas } \\
\text { estadounidenses }\end{array}$} & \multicolumn{2}{|c|}{$\begin{array}{l}\text { Empresas } \\
\text { asiáticas }\end{array}$} \\
\hline & Dólares & $\begin{array}{l}\mathrm{CCA}^{\mathrm{c}} \\
(\%)\end{array}$ & Dólares & $\begin{array}{r}\mathrm{CCA}^{\mathrm{c}} \\
(\%)\end{array}$ & Dólares & $\begin{array}{r}\mathrm{CCA}^{\mathrm{c}} \\
(\%)\end{array}$ \\
\hline 1982 & 9.7 & - & 4.4 & 59.2 & - & \\
\hline 1983 & 7.2 & 11.0 & 3.4 & 67.7 & 0.1 & 100.0 \\
\hline 1984 & 20.7 & 33.4 & 6.4 & 61.9 & 0.3 & 100.0 \\
\hline 1985 & 18.2 & 1.6 & 20.2 & 21.9 & 17.5 & 100.0 \\
\hline 1986 & 30.0 & 8.2 & 36.7 & 15.9 & 35.0 & 100.0 \\
\hline 1987 & 62.1 & 7.1 & 50.8 & 14.6 & 71.8 & 100.0 \\
\hline 1988 & 68.5 & 15.9 & 68.9 & 16.0 & 83.5 & 99.5 \\
\hline 1989 & 72.6 & 11.5 & 88.7 & 12.4 & 81.8 & 99.4 \\
\hline 1990 & 68.1 & 15.1 & 101.5 & 15.7 & 108.1 & 99.6 \\
\hline 1991 & 60.0 & 9.7 & 116.6 & 10.4 & 122.1 & 99.3 \\
\hline 1992 & $\ldots$ & $\ldots$ & $\ldots$ & $\ldots$ & 155.3 & $\ldots$ \\
\hline
\end{tabular}

Fuente: CEPAL, sobre la base de datos suministrados por JAMPRO (División de Comercio Internacional).

a Excluye las exportaciones a la CARICOM. ${ }^{b}$ Las empresas "asiáticas" son en realidad sólo predominantemente asiáticas, puesto que todas las empresas que no son estadounidenses ni jamaiquinas están incluidas en ese rubro. ${ }^{\mathrm{c}}$ Se refiere al porcentaje de las exportaciones sometidas a "corte, confección y acabado", para distinguirlas de las correspondientes al armado de vestuario acogido a la partida 807. 


\section{IV}

\section{Transferencia de tecnología}

Si bien se reconoce universalmente que la industria maquiladora es un medio de emplear un gran número de trabajadores relativamente no calificados, suele pasarse por alto o incluso negarse su valor como vehículo para la transferencia de tecnología. No obstante, no debería subestimarse la importancia que reviste para una economía el hecho de enfrentar a los trabajadores por primera vez a los rigores de un entorno industrial y a las nociones de puntualidad, control de calidad y plazos. Además, para los empresarios locales el armado de tela precortada ofrece un método poco riesgoso de ingresar a la actividad exportadora. Después de todo, mediante los acuerdos de subcontratación el cliente suministra las materias primas, lo que reduce drásticamente las necesidades de capital de operación de la maquiladora. A medida que el industrial recorre esta curva de aprendizaje, y gana confianza y acceso al financiamiento, puede comenzar a importar y cortar telas, y hacer en definitiva sus propios modelos y diseños.

Las maquiladoras nacionales se hallan todavía en las etapas iniciales de su curva de aprendizaje, ya que la mayoría sigue especializada en el armado de ropa. No obstante, la Davon Corporation comenzó hace algunos años a dedicarse al corte, confección y acabado, para una empresa de la zona franca de propiedad de nacionales de la República de Corea, y también para el mercado canadiense, utilizando tela importada del Canadá. Ahora último obtuvo un contrato de una empresa mercantil para la producción de una línea de ropa informal, en virtud del cual tiene la plena responsabilidad de procurarse las materias primas, confeccionar los moldes y cortar las telas, además de efectuar las operaciones normales de costura y acabado. En suma, la empresa jamaiquina hará todo salvo comercializar el producto. Más típico es el caso de Classic Manufacturing, una empresa jamaiquina bien administrada con una planta única situada cerca de la zona franca de Montego Bay. Esta empresa es casi tan antigua (aunque no tan grande) como la $\mathrm{Da}-$ von Corporation, pero jamás ha pensado en hacer otra labor que no sea el armado de pantalones para el mercado estadounidense en virtud de la partida 807.

Puesto que las empresas de propiedad asiática realizan el corte de la mayor parte de la tela que utilizan para confeccionar ropa, cabría concluir que, mediante la capacitación de sus empleados, transfieren más tecnología al país que las empresas estadounidenses o jamaiquinas que operan como subcontratistas de empresas situadas en los Estados Unidos, acogiéndose a la partida 807. Es verdad que en Jamaica la operación de corte la realizan siempre los hombres, mientras que las que operan las máquinas de coser son casi siempre las mujeres. ${ }^{5}$ Además, suele transcurrir un período de capacitación de seis meses antes de que una persona no calificada se transforme en un cortador competente. Por otra parte, la fábrica más grande de vestuario de Jamaica tarda tres meses en capacitar operadores de máquinas de coser, y otros productores manifiestan que tardan hasta seis meses debido a la poca destreza y la falta de rasgos de carácter como disciplina y puntualidad de los que se incorporan a la fuerza de trabajo. El gerente de una empresa de propiedad de nacionales de la República de Corea sostiene que necesita 12 meses para capacitar plenamente a un operador de máquina de coser: su planta produce vestidos para el exclusivo mercado de las boutiques, con telas de diseños y texturas que dificultan la tarea.

Una encuesta salarial efectuada en las fábricas de la zona franca de Kingston en mayo de 1993, prácticamente no mostró diferencias entre los salarios de los cortadores y de los operadores de máquinas de coser (cuadro 6). Si los salarios reflejan los niveles de destreza, entonces, en términos de desarrollo de los recursos humanos, no existe gran diferencia entrè los cortadores y los operadores de máquinas y a lo más se puede concluir que las operaciones de corte, confección y acabado exigen más variedad de destrezas, pero no una mayor destreza, que el armado de ropa acogido a la partida 807.6

Aunque Jamaica posee abundancia de mano de obra no calificada hay una clara escasez de personal calificado, y donde esto es más evidente es en la gestión. De las empresas de propiedad extranjera que

\footnotetext{
$5 \mathrm{El}$ autor de este artículo observó que sólo en dos de las fábricas que visitó había personal masculino que operaba máquinas de coser, pero también en ellas predominaban abrumadoramente las mujeres como operadoras.

${ }^{6}$ Kaplinsky (1993) sostiene lo contrario.
} 
CUADRO 6

Jamaica: Salarios en la industria del vestuario de las zonas francas, mayo de $1993^{\text {a }}$

(Dólares por hora)

\begin{tabular}{|c|c|c|}
\hline & $\begin{array}{l}\text { Salario } \\
\text { mínimo }\end{array}$ & $\begin{array}{r}\text { Salario } \\
\text { medio }\end{array}$ \\
\hline Operador de máquina de coser & 0.34 & 1.13 \\
\hline Aprendiz de operador de máquina de $\operatorname{coser}^{a}$ & 0.34 & 0.68 \\
\hline Cortador & 0.34 & 1.13 \\
\hline Alisador & 0.34 & 1.01 \\
\hline Planchador y acabador & 0.34 & 1.13 \\
\hline Bodeguero & 0.34 & 0.68 \\
\hline Mecánico & 0.39 & 1.13 \\
\hline Aprendiz de mecánico ${ }^{b}$ & 0.39 & 0.56 \\
\hline Personal de mantenimiento & 0.39 & 1.13 \\
\hline Supervisor & 0.51 & 2.25 \\
\hline Cajero pagador & 0.39 & 0.79 \\
\hline Mensajero & 0.34 & 0.39 \\
\hline
\end{tabular}

Fuente: Kingston Free Zone Company Ltd.

a Los salarios están basados en una semana laboral estándar de 40 horas y excluyen el costo de las prestaciones complementarias, cuyo mínimo legal es de $18.8 \%$ (impuestos sobre las nóminas de $11.5 \%$, incluida la contribución del empleador al sistema nacional de seguridad social, nueve feriados nacionales y dos semanas de vacaciones anuales).

b El período de capacitación no debe superar las 12 semanas.

visitó el autor, todas salvo dos relativamente pequeñas eran dirigidas por expatriados. De hecho, incluso las empresas de propiedad jamaiquina recurren a gerentes expatriados. En Montego Bay, por ejemplo, tres grandes fábricas de jamaiquinos están a cargo de nacionales estadounidenses, mientras sus propietarios se dedican sobre todo a conseguir contratos y manejar las finanzas. Los expatriados son caros en comparación con los gerentes locales, y la abundancia de los primeros en las fábricas jamaiquinas refleja la escasez de estos últimos.

Es raro que haya un gerente de planta jamaiquino en las fábricas que confeccionan vestuario de exportación, pero los empresarios de este ramo sostienen que las habilidades están mejorando: hace 10 años se importaban incluso los supervisores; ahora todos los supervisores son jamaiquinos. Lo positivo es que hay numerosos cargos directivos de alto nivel ocupados actualmente por expatriados, cargos que estarán disponibles más adelante para una nueva generación de jamaiquinos formados en disciplinas como la ingeniería industrial. El hecho de saber que estos cargos son muy bien remunerados debería estimular a los jóvenes jamaiquinos a preferir los estudios técnicos en las universidades. ${ }^{7}$ La escasez de

7 Naturalmente que la educación superior no es la única forma de llegar a ser gerente de planta. De los dos gerentes jamaiquinos mano de obra calificada afecta también a la industria de procesamiento de datos, que prefiere contratar a graduados de la enseñanza media con conocimientos de mecanografía. Los propietarios y gerentes de las empresas de este rubro se quejan de que tienen dificultades para contratar operadores para el ingreso de datos, y que los que contratan tienen tan mala formación general que requieren por lo menos tres a cuatro meses de capacitación antes de comenzar siquiera a trabajar en serio. Durante ese período, aunque su productividad es casi nula, hay que pagarles el salario mínimo legal.

Una vez capacitado, el operador suele cambiar de empleador, ya que existe una encarnizada competencia por ese pequeño núcleo bien preparado. ${ }^{8}$ Este es un caso clásico de externalidades: la empresa que incurre en el gasto de capacitar un trabajador no puede recuperar su inversión, de modo que todas las empresas invierten muy poco en la capacitación de nuevos trabajadores. Sería mejor impartir la capacitación básica fuera de la empresa, y que el costo se distribuyera entre todas las empresas del rubro. Esto implicaría una proporción mayor del costo para el aprendiz, pues no habría que pagarle un salario mínimo durante su formación. De hecho, las firmas de procesamiento de datos en el área de Kingston han iniciado un programa de este tipo para los graduados de la enseñanza secundaria, en colaboración con un programa gubernamental de formación profesional denominado Human Employment and Resources Training (HEART).

En Jamaica, el procesamiento de datos ofrece interesantes perspectivas de crecimiento porque está limitado por la oferta más que por la demanda. Los gerentes de las empresas respectivas sostienen que podrían emplear muchos más operadores de estar ellos disponibles. Se les exige alfabetización funcional y buena mecanografía; los aprendices que ya poseen una educación comercial básica pueden aprender fácilmente a manipular los programas para el ingreso de datos y el procesamiento de palabras. No obstante,

entrevistados que trabajan para empresas de propiedad estadounidense, uno es ingeniero industrial diplomado en contabilidad; el otro, en cambio, tiene escasa educación formal, pero administró con éxito su propia fábrica de vestuario acogida a la partida 807 antes de aceptar su actual cargo en la empresa extranjera.

8 Hay también escasez de operadores de máquinas de coser capacitados, en comparación con los capacitables. Pero ellos no se cambian de una compañía a otra, porque las fábricas de vestuario comparten las listas de empleados y se niegan a contratar a un trabajador proveniente de otra empresa sin consultar primero con su empleador previo. En cambio, las firmas de procesamiento de datos compiten en vez de cooperar en el mercado laboral. 
ésta es una industria altamente competitiva en la que los jamaiquinos tienen que competir con empresas de todo el mundo, de modo que los salarios siguen siendo bajos pese a la aguda escasez de personal.

Las empresas que operan en la industria del ingreso y procesamiento de datos tienen que mantenerse a la vanguardia de los adelantos tecnológicos en materia de programas y equipos para seguir siendo competitivas, cosa que parecen estar haciendo con éxito en Jamaica. Muchas empresas están incorporando aparatos lectores de imágenes en sus operaciones, ya que estos dispositivos aumentan notoriamente la productividad en algunos tipos de ingreso de datos.

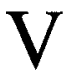

\section{Costos de la mano de obra}

Las maquiladoras están sujetas a las mismas leyes laborales que toda empresa que opere en el país. El salario mínimo en 1993 era de 300 dólares jamaiquinos por 40 horas semanales, lo que equivalía a 34 centavos de dólar estadounidense por hora al tipo de cambio entonces vigente. Todo trabajo realizado fuera de la jornada laboral de ocho horas diarias o efectuado en día sábado, debe pagarse con un recargo de $50 \%$, y si se realiza en días domingo o feriado, se recarga en $100 \%$.

Los sistemas de remuneración a destajo rigen en casi todas las fábricas de vestuario y empresas de procesamiento de datos de la isla, y por lo tanto el salario mínimo es sólo una base. Naturalmente que los trabajadores que acostumbran a producir mucho menos que el equivalente al salario mínimo son despedidos. El gerente de una planta de vestuario de la zona franca reconoció que la mitad de sus operadores de máquinas de coser sólo ganaba el salario mínimo. $\mathrm{El}$ gerente de otra fábrica del rubro, situada fuera de la zona franca, señaló que su empresa exigía que los operadores produjeran con el sistema de pago a destajo al menos $80 \%$ del equivalente al salario mínimo para que pudieran conservar su empleo.

Con incentivos tan poderosos a la productividad, los salarios medios son muy superiores a los mínimos. Una encuesta efectuada a las empresas de la zona franca de Kingston en mayo de 1993 reveló, por ejemplo, que sin considerar los pagos por horas extraordinarias, la remuneración media de los operadores de máquinas de coser (1.13 dólares estadounidenses por hora) triplicaba con creces el salario mínimo ( 0.34 dólares estadounidenses por hora). Incluso el salario medio de los aprendices en su primer trimestre de trabajo duplicaba el salario mínimo (cuadro 6).

Un sistema similar rige para los operadores encargados del ingreso de datos, a quienes se les paga por tecla digitada, o bien reciben el salario mínimo más un bono de productividad. No hay datos de encuestas sobre esta industria, pero los gerentes mencionaron en junio de 1993 salarios medios del orden de 500 a 600 dólares jamaiquinos semanales, lo que equivale a una cifra que fluctúa entre 56 y 68 centavos de dólar estadounidense por hora. Es un monto algo reducido para empleados que poseen más educación formal que el típico operario fabril, pero cabe señalar que los primeros trabajan en oficinas tranquilas y dotadas de aire acondicionado, con horarios flexibles, de modo que disfrutan de un mayor ingreso no pecuniario que los operarios de la industria del vestuario.

La remuneración a destajo no se utiliza en las dos plantas de montaje eléctrico/electrónico de la isla, pero sus empleados tienen derecho a percibir bonos por productividad colectiva, y ganan mejores salarios que los operadores de máquinas de coser. ${ }^{9}$ En cuanto al telemercadeo, los operadores telefónicos que constestan las llamadas telefónicas gratuitas para reservas de hoteles y cosas similares ganan poco más que el salario mínimo. En cambio, los que venden directamente por teléfono ganan un salario base más una comisión por ventas, y a algunos les va muy bien de acuerdo con los estándares jamaiquinos, además de laborar en oficinas agradables y con aire acondicionado.

Aparte del salario básico, el empleador tiene que pagar también impuestos sobre las nóminas ascendentes a $11.5 \%$. A la cifra anterior se suma el $6.5 \%$

\footnotetext{
${ }^{9}$ Ambas plantas difieren asimismo de las fábricas de vestuario en que utilizan menos la mano de obra femenina. La planta de montaje eléctrico cuenta sólo con personal masculino, en tanto que la de montaje electrónico tiene un número aproximadamente igual de personal masculino y femenino que realiza tareas similares por igual remuneración.
} 
que se deduce de la remuneración del empleado, el que recibe las prestaciones del sistema nacional de seguridad social. Todos los empleados tienen derecho a nueve días feriados y dos semanas de vacaciones anuales pagadas, lo que añade otro $7.3 \%$ al costo de la mano de obra. Asimismo, tienen derecho legal a disfrutar de hasta dos semanas de licencia por enfermedad cada año, y sólo se les exige certificado médico por más de dos días consecutivos de licencia. Para desalentar el mal uso de este derecho, muchas empresas pagan a fines de año a sus trabajadores los días de licencia por enfermedad no utilizados en la forma de una gratificación navideña. La empleada mayor de 18 años de edad que ha trabajado un mínimo de 12 meses tiene derecho a 12 semanas de licencia de maternidad, ocho de las cuales son con sueldo completo.

Las empresas suelen otorgar a sus empleados prestaciones complementarias no exigidas por la ley, tales como bonos por puntualidad, almuerzos gratuitos o subsidiados, transporte gratuito hasta un lugar céntrico (lo que es habitual en Montego Bay), seguro de salud complementario, licencias adicionales por vacaciones, enfermedad y maternidad, y pensión de jubilación. Estas prestaciones complementarias son más generosas en las fábricas de ropa y las plantas de montaje que en las empresas de procesamiento de datos o de telemercadeo.
Las leyes nacionales son bastante permisivas en cuanto a la reducción y despido de personal. Durante los primeros tres meses puede darse término al empleo de un trabajador sin aviso previo y sin indemnización. Pasado ese lapso, se le debe avisar con dos semanas de antelación (o pagarle el equivalente a esas dos semanas), a menos que el trabajador haya servido por más de cinco años, en cuyo caso dicho aviso debe darse con cuatro semanas de anticipación. Transcurridos diez años de servicio, el aviso reglamentario es de seis semanas y después de 15 años es de ocho semanas. Si se pone término al empleo por exceso de personal, existe otra disposición reglamentaria que estipula una indemnización por cesantía equivalente a dos semanas de sueldo por cada año de servicio prestado entre dos y diez años de trabajo, y una indemnización de tres semanas de sueldo por cada año de servicio por encima de los diez años de trabajo.

La actividad sindical está permitida en todo el país, siempre que la mayoría de los trabajadores de una empresa vote a favor de establecer el sindicato, pero hasta ahora no hay una sola empresa sindicalizada en la zona franca. El personal de algunos productores de vestuario que operan fuera de las zonas francas está sindicalizado, y las relaciones laborales en los últimos años han sido satisfactorias.

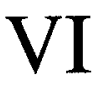

\section{Eslabonamientos hacia adelante}

Dado que el gobierno se muestra renuente a permitir que las empresas de las zonas francas compitan con las empresas nacionales protegidas, las zonas francas carecen prácticamente de eslabonamiento hacia adelante con el resto de la economía. La legislación de las zonas francas contempla la exportación de bienes desde esas zonas al territorio aduanero jamaiquino previo pago de derechos y con el consentimiento del Ministerio de Industria. Hasta la fecha este consentimiento sólo se ha otorgado a una empresa: un fabricante sudcoreano de calzado de cuero que vende el $10 \%$ de su producción en Jamaica.

Las firmas que operan fuera de las zonas francas, acogidas a las disposiciones de la Ley de Fomento de la Industria de Exportación, enfrentan graves obstáculos si intentan producir para el mercado local o subregional, de modo que todas han optado por exportar íntegramente su producción a mercados fuera de la CARICOM. La única forma en que pueden abastecer legalmente el mercado local es mediante una separación física en la fábrica entre los bienes procesados para la exportación y los bienes procesados para los mercados del país y de la CARICOM. El tamaño reducido del mercado local hace que esto no resulte atractivo. Incluso los exportadores que comienzan como productores de ropa para el mercado local, a poco andar se especializan íntegramente en el mercado de exportación, como muy bien lo ilustra la trayectoria de la Davon Corporation.

A fines de la década de 1970, la Davon Corporation producía uniformes y otras vestimentas que vendía en Jamaica y exportaba a los países de la CARICOM. En 1981 la empresa comenzó a expandirse, armando ropa para el mercado estadounidense en 
virtud de contratos acogidos a la partida 807. En 1984 el mercado de la CARICOM se derrumbó debido a restricciones comerciales y el mercado jamaiquino siguió contrayéndose a causa de la recesión económica. La Davon Corporation optó por abandonar la producción para el mercado interno y el de la CARICOM, y expandir aquélla para el mercado estadounidense. Todos los trabajadores que habían venido produciendo para el mercado interno fueron despedidos y en su lugar se contrataron nuevos operarios no calificados y se les capacitó. ${ }^{10}$ El motivo es el sistema de remuneración a destajo que rige en esa empresa. A juicio del gerente de la planta, los operarios estaban acostumbrados a recibir 35 minutos de crédito por un par de pantalones que, conforme a los estándares internacionales, no representaban más de 19 minutos de trabajo. Por lo tanto, era más fácil cambiar el personal que disminuir el salario a destajo ya consagrado. Naturalmente, como había falta de especialización y las tandas de producción para el mercado interno eran cortas, la productividad era escasa, por lo que hubo que ofrecer salarios a destajo generosos.

En los últimos años, la economía jamaiquina mejoró y la Davon Corporation decidió volver a vender uniformes en el mercado interno, donde ha- bía adquirido ya una reputación. Sin embargo, la empresa ya no produce esos uniformes, sino que subcontrata su producción y los provee con su propia etiqueta directamente a hospitales, hoteles y demás instituciones. Así, la Davon Corporation es una subcontratista de empresas estadounidenses y a su vez subcontrata empresas jamaiquinas para abastecer el mercado local. La firma no ha vuelto aún a vender a la CARICOM.

Este entorno regulador da como resultado una industria del vestuario segmentada. Un segmento es moderno, en gran escala, eficiente, altamente productivo y orientado exclusivamente al mercado de exportación. El otro es en pequeña escala, en gran medida no especializado, con escasa productividad y orientado al mercado interno y, en mucho menor medida, a la CARICOM. Casi no existe contacto entre ambos segmentos; ni los trabajadores ni los gerentes se trasladan de uno a otro. El gobierno prohíbe las ventas de los exportadores en el mercado interno porque desea proteger el segmento ineficiente de la industria. No obstante, al país ingresa un contrabando considerable (a través de los comerciantes maleteros, no de los exportadores), por lo que la industria local protegida sólo proporciona un $20 \%$ de la ropa que adquieren los jamaiquinos.

\section{VII}

\section{Eslabonamientos hacia atrás}

Las maquiladoras no han desarrollado eslabonamientos hacia atrás por la misma razón por la que no los han desarrollado hacia adelante: esto es, por la política gubernamental. Para que una entidad comercial jamaiquina pueda suministrar un producto o servicio a una empresa de la zona franca o acogida a la Ley de Fomento de la Industria de Exportación, tiene que estar registrada como empresa exportadora. El proceso de registro es burocrático, confuso, plagado de múltiples formularios y sujeto a considerable discrecionalidad administrativa. Por ejemplo, uno de los requisitos que deben cumplir los exportadores es obtener todos los meses un certificado de conformidad tributaria que tiene que ser timbrado por seis organismos diferentes.

10 Como la empresa Davon está sindicalizada, se negoció el pago de una indemnización para los operadores de máquinas de coser que fueron despedidos.
Este papeleo desalienta la adquisición local incluso de pequeñas partidas como útiles de escritorio, pese a la disposición de las empresas a abastecerse localmente de algunos insumos. En la zona franca de Montego Bay, por ejemplo, la Hanover Manufacturing, que se ocupa del montaje de equipo eléctrico, estaba interesada en agregar mayor valor local a su producto mediante la importación de tornillos sin pintar y la subcontratación de la pintura con una empresa local. Dos empresas se interesaron en suscribir el contrato, hasta que descubrieron el costo en tiempo y dinero que significaba obtener y mantener un registro de exportación. La Hanover Manufacturing sigue importando tornillos pintados $\mathrm{y}$ listos para el montaje.

En este entorno regulador, no es de extrañar que las maquiladoras hallen con frecuencia que los productos nacionales no pueden competir con las impor- 
taciones en precio y calidad. Las empresas no acogidas a la Ley de Fomento de la Industria de Exportación y situadas en el territorio aduanero se benefician de una rebaja tributaria de $7.5 \%$ por las "exportaciones" que realizan a las empresas acogidas a dicha ley y a las de la zona franca, que es igual a la que obtienen por las exportaciones a mercados ajenos a la CARICOM; pero esto no basta para superar la desventaja competitiva que causan los obstáculos burocráticos y los impuestos a las materias primas importadas.

Ningún exportador adquiere cartones u otro material de embalaje a las empresas locales. La opinión unánime de los gerentes de las fábricas de vestuario y de las plantas de montaje eléctrico/electrónico entrevistados por el autor fue que el embalaje nacional costaba mucho más que el embalaje importado de similar calidad. Cuando la Fargo Electronics comenzó su producción en 1992 en la zona franca de Montego Bay, su gerente trató de abastecerse en el mercado local de varios materiales de embalaje, como cajas de cartoncillo y embalaje de espuma plástica. En todos los casos, la espera para que se iniciara la producción era muy larga, los costos eran elevados, y se exigía el pago inicial de todos los gastos de utillaje.

No obstante, las cajas de cartoncillo son artículos voluminosos en que el flete representa una gran proporción del costo de importación cif, de modo que existe un incentivo para obtener este insumo en el país. El productor más grande de vestuario en Jamaica (East Ocean Textiles, una empresa de nacionales de Hong Kong que emplea a casi 4 mil trabajadores en la zona franca de Kingston) instaló una fábrica de cajas dentro de su propia planta en septiembre de 1985. La fábrica está dotada de equipo moderno, incluidos una caldera, la única doble enfrentadora de la isla, máquinas de corte y plegado e impresoras. Un total de 35 empleados produce un

\section{VIII}

\section{Conclusión}

El éxito de Jamaica en la industria maquiladora obedece en parte a factores que escapan al control de su gobierno. El procesamiento de datos y el te-

11 Para mayor información sobre la fábrica de cajas de la East Ocean Textiles, véase Kingston Free Zone Company Ltd. (1992). promedio de 40 mil cajas mensuales, una pequeña parte de las cuales se vende a otras empresas de la zona franca. ${ }^{11}$

Hay una actividad que podría interpretarse como un eslabonamiento hacia atrás: la subcontratación, por empresas de la zona franca, de empresas que operan en el territorio aduanero. Los productores de vestuario subcontrataron una parte considerable de la producción en 1987 y 1988 , cuando las exportaciones de ropa estaban en auge, y lo siguen haciendo hoy, aunque en menor cuantía. Pero estos subcontratos sólo pueden otorgarse a las firmas que operan acogidas a las disposiciones de la Ley de Fomento de la Industria de Exportación, por lo que en realidad se trata de compras de servicios que se efectúan dentro del sector de la industria maquiladora y no eslabonamientos con la economía nacional. Además, a diferencia del caso de los subcontratos en la República de Corea, donde los bienes procesados fuera de la zona tienen que ser componentes o productos intermedios de procesos productivos que culminan en la zona franca industrial (Healey y Lütkenhorst, 1989, p. 28), el subcontratista jamaiquino lleva a cabo todo el proceso que de otro modo efectuaría la firma contratante. Por ejemplo, Bongwon Apparel, una empresa de nacionales de la República de Corea que opera en la zona franca de Kingston, subcontrata la fabricación de blusas con Davon Corporation, empresa acogida a la Ley de Fomento de la Industria de Exportación. Davon Corporation recibe de Bongwon Apparel un contenedor con telas, hilos y botones, luego corta, confecciona y acaba las blusas, y devuelve la ropa terminada a Bongwon Apparel.

En suma, la subcontratación que se realiza en Jamaica no crea eslabonamientos de especie alguna con la economía interna. No los hay hacia atrás entre las maquiladoras y el resto de la economía, y éste es el resultado - intencional o no- de la política gubernamental del país. lemercadeo se benefician de la proximidad con los Estados Unidos y del hecho de que los jamaiquinos hablan inglés. Las exportaciones de vestuario se ven estimuladas por el acceso preferencial de Jamaica, mediante asignaciones de cuotas, a mercados protegidos. Rara vez se observa el montaje en el país 
de aparatos electrodomésticos, juguetes o equipo eléctrico que no tengan cuotas asignadas en los países industriales.

No obstante, el papel que ha desempeñado el gobierno de Jamaica en el desarrollo de las maquiladoras dista de ser despreciable. En primer lugar, es el gobierno el que otorga las concesiones tributarias a las empresas en la forma de un régimen de libre comercio o como incentivos en virtud de la Ley de Fomento de la Industria de Exportación. Además, ha alentado la inversión mediante actividades de promoción, consistentes en ofrecer en alquiler los galpones industriales y facilitar el otorgamiento de permisos de trabajo a gerentes y personal técnico expatriados.

Las maquiladoras ofrecen empleo productivo a más de 30 mil jamaiquinos. Como la mayoría de las ocupaciones exigen poca capacitación y los gerentes de plantas son en su mayoría expatriados, resulta tentador concluir que ha habido poca transferencia de tecnología y poco desarrollo de los recursos humanos del país. El autor considera que esa conclusión es injustificada, por dos razones. Ante todo, muchos de esos trabajadores han sido puestos por primera vez en contacto con las nociones de puntualidad, control de calidad y plazos, en suma, con una ética laboral. Además, hay puestos calificados que actualmente ocupan los expatriados. Como ellos son más caros que los empleados locales, los jamaiquinos llenarán gradualmente tales puestos a medida que se cuente con postulantes idóneos. En realidad, así ha ocurrido ya en el caso de los supervisores, que ahora se reclutan íntegramente en el país.

Una falla conspicua de las maquiladoras en Jamaica es la falta casi absoluta de eslabonamientos con la economía interna. Los eslabonamientos hacia adelante son frustrados por políticas destinadas a proteger de la competencia a las empresas que producen para el mercado interno: salvo raras excepciones, el gobierno no permite que los trabajadores jamaiquinos y sus familias compren los productos que maquilan. No se han desarrollado eslabonamientos hacia atrás porque las empresas nacionales encaran obstáculos graves e insuperables cuando tratan de vender sus productos y servicios a los exportadores. El gobierno jamaiquino no restringe las maquiladoras a enclaves físicos: en la mayoría de los casos están facultadas para operar plantas en cualquier punto de la isla. Sin embargo, lo trágico es que sus políticas sí las confinan a enclaves económicos aislados del resto de la economía.

Los autores que tratan este tema con frecuencia suponen que las maquiladoras tienen una clara inclinación a abastecerse de materias primas en el exterior, de modo que no habrá eslabonamientos hacia atrás, cualquiera sea la política gubernamental. Es posible señalar maquiladoras de zonas francas que importan del exterior prácticamente todos sus insumos materiales. Hay ejemplos bien conocidos, aparte de Jamaica, en la República Dominicana y la frontera septentrional de México. Por otra parte, también existen zonas donde los exportadores han establecido eslabonamientos importantes con los productores nacionales.

Se sabe que las industrias maquiladoras de países tan diversos como la República de Corea, Mauricio y Santa Lucía, adquieren una cantidad importante de insumos materiales a los productores locales. Cuando la República de Corea inauguró la zona franca industrial Mason en 1971, las fábricas locales sólo proveían $3.3 \%$ de las materias primas y bienes intermedios que procesaba la zona. Esta proporción aúmentó a $25 \%$ en sólo cuatro años, y llegó finalmente a 44\% (Healey y Lütkenhorst, 1989, pp. 2432; CET, 1991, p. 331-343). Mauricio, una pequeña isla del Océano Indico, también inauguró una zona franca industrial en 1971 que atrajo una considerable inversión china en fábricas de vestuario. En 1982 los productores nacionales abastecían $41 \%$ de todos los insumos intermedios que necesitaba esa industria, lo que incluía casi todas las cajas de cartoncillo y una gran parte de las telas, hilos, botones y guarniciones (Hein, 1989, p. 48). En Santa Lucía, una pequeña isla caribeña con 137 mil habitantes, 15 maquiladoras fabrican y arman vestuario, equipo eléctrico y artículos plásticos de fantasía. Catorce de ellas compran todas sus cajas de cartoncillo a una fábrica local, y dependen también de los proveedores locales para los insumos intermedios adicionales (Willmore, 1993).

Con la aplicación de políticas apropiadas, estos tres países han facilitado los eslabonamientos entre sus maquiladoras y la economía interna. La República de Corea, Mauricio y Santa Lucía difieren en muchos sentidos, pero tienen una cosa en común: las autoridades permiten que los exportadores indirectos importen insumos materiales a precios liberados de derechos, y alientan a los productores nacionales a abastecer a las maquiladoras. Esto no ocurre en países como Jamaica o la República Dominicana, donde, como consecuencia de la política gubernamental, las maquiladoras importan todas sus materias primas y bienes intermedios.

(Traducido del inglés) 


\section{Bibliografía}

CEPAL (Comisión Económica para América Latina y el Caribe) (1990): Las zonas francas industriales y la mujer en el Caribe (LC/L.586 (MDM. 11/5)), Puerto España.

CET (Centro de las Naciones Unidas sobre las Empresas Transnacionales) (1991): The Challenge of Free Economic Zones in Central and Eastern Europe. International Perspectives, Nueva York. Publicación de las Naciones Unidas, $\mathrm{N}^{\circ}$ de venta E.90.II.A.27.

Healey, Derek y Wilfried Lütkenhorst (1989): Export processing zones: the case of the Republic of Korea, Industry and Development, $\mathrm{N}^{\circ} 26$, Viena. Publicación de la Organización de las Naciones Unidas para el Desarrollo Industrial (ONUDI), $\mathrm{N}^{\circ}$ de venta E.89.III.E.1.

Hein, Philippe (1989): Structural transformation in an island country: the Mauritius Export Processing Zone (1971 to 1988), UNCTAD REVIEW, Vol. 1, N ${ }^{\circ} 2$, Ginebra, Conferencia de las Naciones Unidas sobre Comercio y Desarrollo
(UNCTAD). Publicación de las Naciones Unidas, $\mathrm{N}^{\circ}$ de venta E.89.II.D.20.

Instituto de Planificación de Jamaica (1993): Economic and Social Survey Jamaica 1992, Kingston.

Kaplinsky, Raphael (1993): Export processing zones in the Dominican Republic: transforming manufactures into commodities, World Development, Nueva York, Pergamon Press Ltd.

Kingston Free Zone Company, Ltd. (1992): Zoning In, vol. 3, No 1 , Kingston, enero.

Roberts, Matthew W. (1991): Export processing zones in Jamaica and Mauritius: Evolution of an export-oriented development model, tesis de grado, Department of Political Science, Indiana University, mimeo.

Willmore, Larry (1993): Export Processing in Saint Lucia: Ownership, Linkages and Transfer of Technology (WP/93/14), Puerto España, CEPAL. 